\title{
ANALISE EXPERIMENTAL DE PILARES DE CONCRETO ARMADO, REFORÇADOS COM CONCRETO AUTO ADENSÁVEL E CONECTORES
}

\section{Experimental Analysis of Reinforced Concrete Columns Strengthened with Self Compacting Concrete and Connectors}

\author{
Diego Borja Ferreira ${ }^{1}$, Ronaldo Barros Gomes ${ }^{2}$, Alessandra Luciano Carvalho ${ }^{3}$ \\ Recebido em 28 de novembro de 2013; recebido para revisão em 06 de março de 2014; \\ aceito em 07 de abril de 2014; disponivel on-line em 16 de maio de 2014.
}

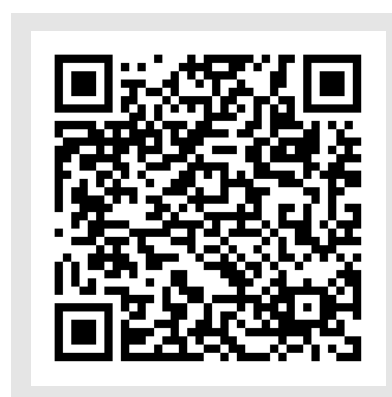

PALAVRAS CHAVE:

Pilares;

Rreforço estrutural;

Concreto.

\section{KEYWORDS:}

Columns;

Strutural Strengthening;

Concrete.

\begin{abstract}
RESUMO: O estudo de reforço e reabilitação de estruturas de concreto armado cada vez mais se torna necessário na construção civil. As falhas nas etapas de projeto, de execução, uso e manutenção bem como o uso de materiais de construção de baixa qualidade podem levar a essa necessidade, somando-se a esse fator a mudança funcional da estrutura. 0 reforço de estrutura se justifica sempre que houver necessidade de aumentar sua capacidade portante. Existem poucos estudos do comportamento dessas estruturas reforçadas o que dificulta a criação de parâmetros que contribuam para a elaboração desses projetos. Nesta pesquisa, foi avaliado o comportamento de pilares de concreto armado solicitados à compressão e excentricidade em apenas uma direção, com uma seção inicial de $120 \mathrm{~mm}$ x $250 \mathrm{~mm}$ e altura de $2000 \mathrm{~mm}$, reforçados na região comprimida com uma camada de $35 \mathrm{~mm}$ de concreto auto adensável. Como armadura de interação, foram utilizados parafusos conectores. Neste estudo as principais variáveis são a posição e a taxa de aço dos conectores. Os pilares reforçados apresentaram aumento na carga de ruptura, em função do aumento da taxa de conectores. Um dos problemas encontrados foi o desplacamento da camada de concreto do reforço próximo à carga de ruptura, sendo necessários outros estudos para solucionar esse fato. Ocorreu ainda uma redução dos deslocamentos horizontais dos pilares, devido à diminuição da ductilidade. Esses resultados mostram a eficiência da técnica de reforço adotada.
\end{abstract}

ABSTRACT: Studying strengthening and rehabilitation in reinforced concrete structures is an ever-growing necessity in civil construction. Flaws during design, execution, use, and maintenance, as well as the use of poor quality construction materials and a structure's functional change may all lead to this necessity. Strengthening a given structure is justified whenever it becomes necessary to increase its bearing capacity. The small number of studies which analyse the behaviour of strengthened structures makes it difficult to establish parameters that may contribute to designing such projects. This research assessed the behaviour of reinforced concrete columns under compression and one-way eccentricity, with an initial section of $120 \mathrm{~mm} \times 250 \mathrm{~mm}$ and height of $2000 \mathrm{~mm}$, strengthened in the compressed area with a $35 \mathrm{~mm}$ layer of self-compacting concrete. Connector screws were used as interaction reinforcement. The main variables were the connectors' position and steel rate. Strengthened columns showed an increase in rupture load due to the increase of connectors' rate. One of the problems detected was the concrete reinforcement layer spalling near the rupture load, whose solution requires further research. There was also a reduction in columns' horizontal displacements, caused by a decrease in ductility. These results show the effectiveness of the strengthening technique employed.

\footnotetext{
* Contato com o autor:

${ }^{1}$ e-mail : borjadiego5@gmail.com

(D. B. Ferreira )

2e-mail : rbggomes@gmail.com

Professor PHD da Escola de Engenharia Civil (EEC) da Universidade Federal de Goiás (UFG).

33e-mail : carvalhoal@hotmail.com (A. L. Carvalho)

Professora Dra. Pontifícia Universidade Católica - GO - (PUC-GO)
}

Mestrando do Curso de Mestrado em Engenharia Civil (CMEC) Escola de Engenharia Civil (EEC) Universidade Federal de Goiás (UFG). 


\section{INTRODUÇÃO}

Vários são os problemas estruturais encontrados na construção civil que podem levar as edificações à ruína. Dentre eles podem ser citados, as falhas de projeto e execução, uso de materiais de baixa qualidade e a mudança funcional da estrutura. $\mathrm{O}$ estudo da situação e do comportamento dessas estruturas é de grande importância para que se possa executar uma intervenção através de métodos de reforço. São inúmeros os materiais e procedimentos de recuperação e reforço estrutural existentes na construção civil, podendo-se citar: o uso de grautes, concreto auto adensável (CAA), fibra de carbono, protensão exterior, uso de concreto projetado, aumento da taxa de armadura, chapas ou perfis metálicos e aumento da seção transversal existente. Este último exige $\mathrm{o}$ atendimento a requisitos que garantam a sua eficácia, dentre os quais se destaca a aderência entre concretos do substrato e reforço.

Segundo Valle (1983), só se deve executar reforço com perfis metálicos se não for viabilizado o uso de concreto, pois a eficácia deste recurso depende do bom desempenho dos nós e das transmissões de ações entre a estrutura original e o reforço, condição que não é facilmente alcançada. Este artigo tem por objetivo analisar o comportamento estrutural de pilares reforçados na região tracionada com aplicação de concreto, uma vez que essa técnica é uma das mais empregadas na construção civil. Os pilares deste estudo são submetidos à flexo-compressão reta, utilizando parafusos conectores com o objetivo de aumentar a interação entre o concreto do reforço e substrato.

\section{REVISÃO BIBLIOGRÁFICA}

O reforço de um elemento por encamisamento consiste no aumento da seção transversal pela adição ou não de uma armadura. Esta técnica é naturalmente mais adequada quando há necessidade de aumentar a resistência das zonas comprimidas, de incrementar as dimensões da secção ou de adicionar armaduras ficando estas no interior da seção. (GOMES, \& APPLETON, 1998).

Dentre as pesquisas existentes a respeito de reforço de pilares por aumento da seção transversal podem ser citados os de Omar (2006), Sahb (2008) e Nascimento (2009). Nestes três estudos foram utilizados pilares com a mesma seção transversal e seguindo o mesmo projeto de armaduras, ilustrado na Figura 1.

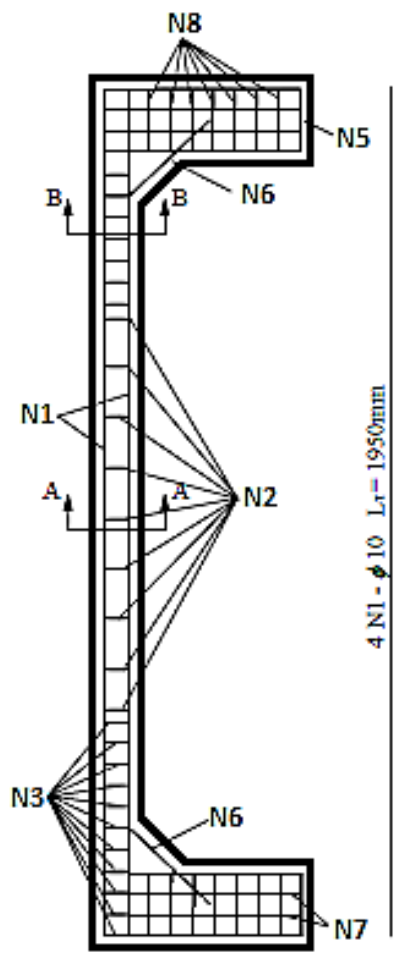

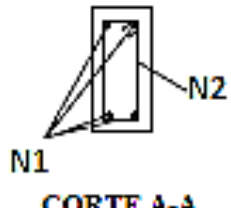

CORTE A-A
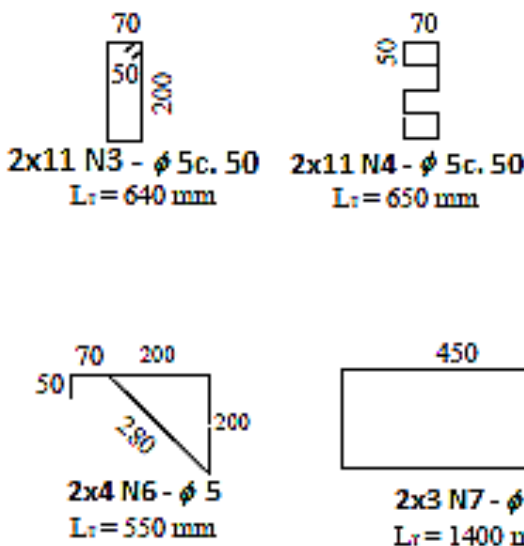

FIGURA 1: Detalhamento das armaduras.
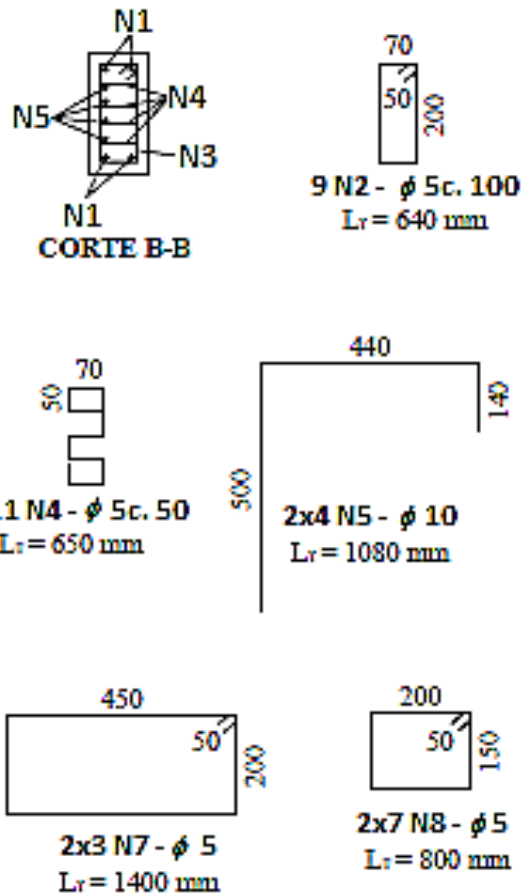

$N 2-\$ 5 c .10$

440

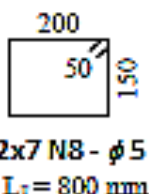

Fonte: ADORNO (2004). 
Omar (2006) desenvolveu seus estudos verificando o aumento da capacidade portante em vários pilares reforçados por acréscimo de uma camada de concreto auto adensável (CAA) em diferentes faces do elemento estrutural.

Os pilares (originais) empregados no estudo foram inicialmente pré-carregados até o início do escoamento da armadura tracionada e depois descarregados e retirados do pórtico de reação. Em seguida, começaram a ser preparados para a realização do reforço.

Para a execução do reforço dos pilares de Omar (2006) foram realizadas as seguintes etapas: escarificação por meio de apicoamento, instalação de conectores utilizando resina epóxi, colagem de extensômetros de resistência elétrica na armadura de reforço.

Os pilares reforçados de Omar (2006) foram desenvolvidos utilizando concreto auto adensável no reforço, armados com barras de diferentes diâmetros $\Phi 10 \mathrm{~mm}$ e $\Phi 12 \mathrm{~mm}$, com conectores em forma de estribos com diâmetro de Ф $5 \mathrm{~mm}$. As camadas de concreto foram moldadas em diferentes faces (tracionadas, comprimidas e ambas as faces), (Figura 2). Após a moldagem do reforço foram instalados extensômetros de resistência elétrica no concreto, posicionados na camada de reforço e na região de interação entre reforço e substrato (Figura 3). Omar (2006) concluiu que todos os pilares reforçados apresentaram carga de ruptura superior a 2,1 vezes a carga do pilar de referência, confirmando a eficiência de todos os tipos de reforço executados. Conclui ainda que apenas os pilares reforçados na face comprimida apresentaram desplacamento do concreto do reforço, indicando que a aderência do concreto novo com o velho deve ser melhorada.

Os pilares reforçados na face comprimida e tracionada simultaneamente, não apresentaram indícios de desplacamento do concreto do reforço. Mesmo sendo a diferença da taxa de armadura colocada no reforço da face tracionada desses pilares de $36 \%$, a diferença da carga de ruptura entre eles foi apenas de $4,4 \%$ e $2,3 \%$, respectivamente.

O estudo de Sahb (2008) foi desenvolvido de forma semelhante à de Omar (2006) tendo como principal diferença o uso de parafusos chumbadores, em substituição aos conectores que funcionavam como estribos. Outra importante diferença foi à adição da camada de concreto apenas na região tracionada. Seu principal objetivo era minimizar os efeitos do desplacamento do reforço impedindo com isso a ruptura brusca das peças.

Os chumbadores eram distribuídos em diferentes posições e quantidades (Figura 4).
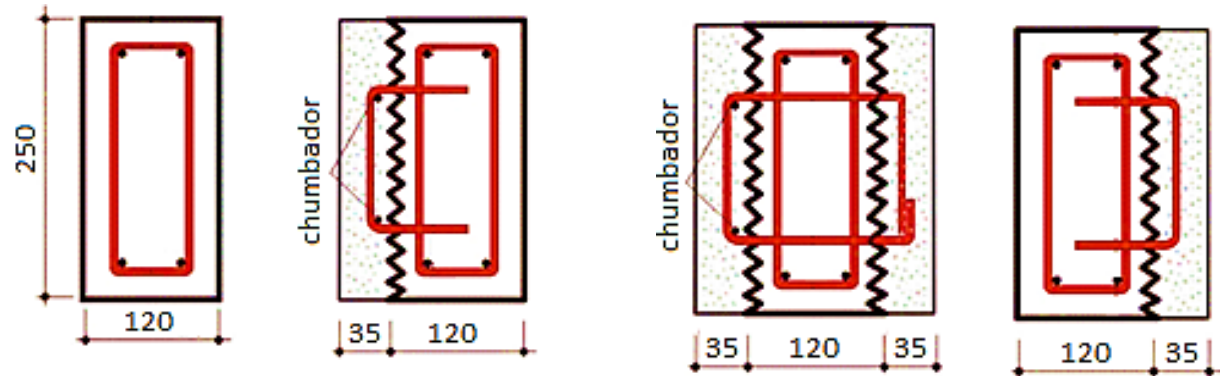

FIGURA 2: Posicionamento dos estribos nas camadas de reforço de concreto (CAA). Fonte: OMAR (2006). 

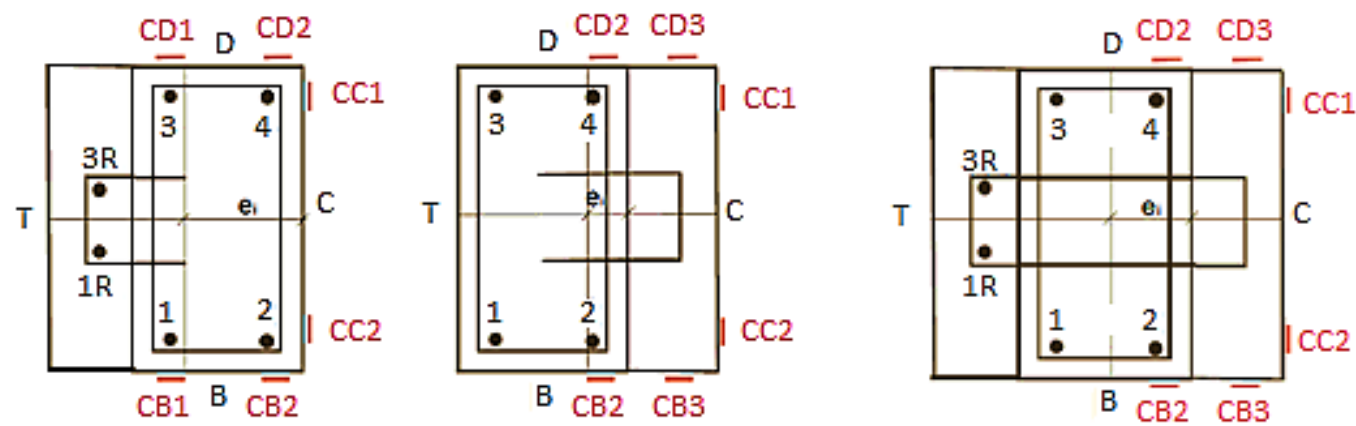

FIGURA 3: Posicionamento dos extensômetros no concreto. Fonte: OMAR (2006).
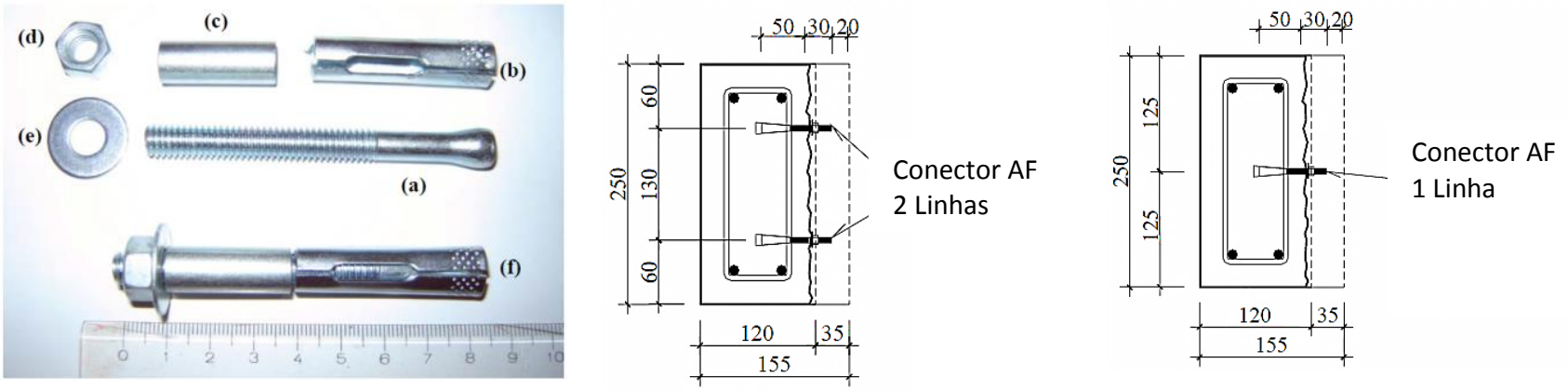

FIGURA 4: Posicionamento dos conectores: a) parafuso cônico, b) jaqueta, c) prolongador,

d) porca, e) arruela, f) parafuso completo.

Fonte: SAHB (2008).

Os resultados do estudo de Sahb (2008) indicam que todos os pilares reforçados apresentaram carga de ruptura superior à carga de ruptura do pilar original de referência. Em alguns pilares a ruptura foi do tipo frágil, com desplacamento da camada de reforço.

O pilar com a maior quantidade de chumbadores rompeu com desplacamento da camada de reforço e também foi evidenciada tendência de esmagamento do concreto na região central do pilar. No que diz respeito aos chumbadores, em nenhum dos casos estudados houve ruptura por cisalhamento dos chumbadores utilizados.
O trabalho de Nascimento (2009) baseou-se nesses estudos citados, de forma que foi feito a análise de pilares reforçados na região comprimida com o emprego de uma camada de concreto auto adensável submetidos à flexo-compressão reta, utilizando como conectores entre o substrato e o reforço estribos abertos ancorados nos estribos já existentes no substrato das peças. Para tanto foi necessário confeccionar sulcos no substrato das peças até a região dos estribos para ancorar os conectores utilizados, esquema dos conectores apresentado na Figura 5.

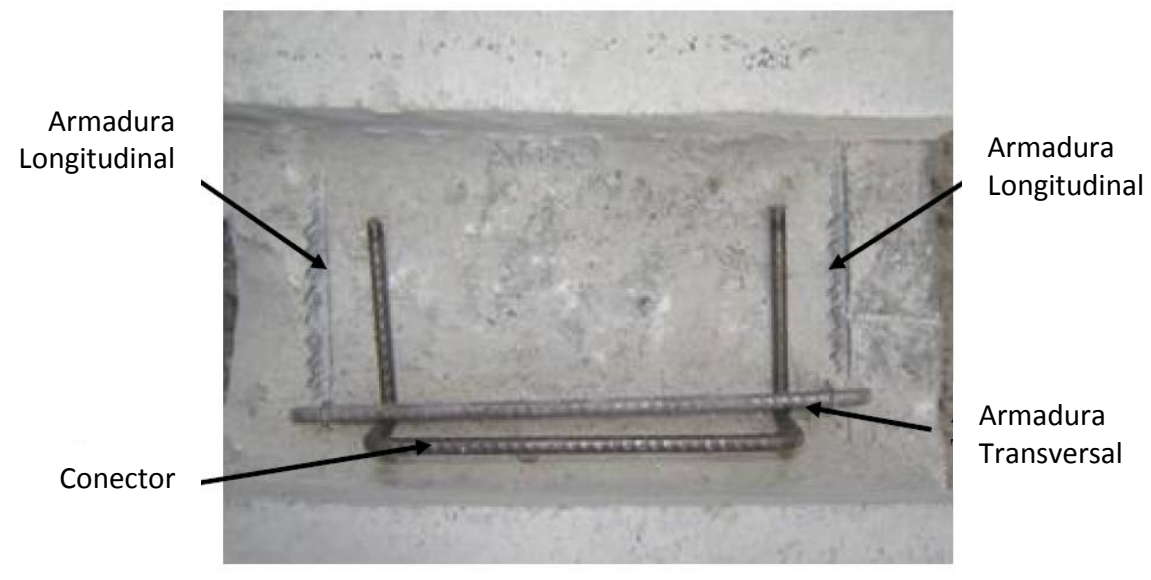

FIGURA 5: Instalação dos estribos conectores.

Fonte: NASCIMENTO (2009). 
Todos os pilares reforçados tiveram um ganho de carga em relação ao pilar de referência original. Não só a quantidade de conectores, mas também sua localização influenciaram na carga e no modo de ruptura dos modelos ensaiados. Foi possível observar que tanto a distância em relação ao centro quanto o espaçamento adotado entre os conectores exercem grande influência na carga de ruptura e, principalmente, o modo de ruptura dos pilares ensaiados a flexo-compressão.

Embora todos os pilares ensaiados nos trabalhos anteriores, Omar (2006), e Sahb (2008), tenham apresentado resultados com aumento da capacidade portante, no geral todos romperam de maneira brusca por desplacamento do reforço. Nascimento conseguiu em seus estudos que um de seus pilares tivesse aumento da capacidade portante e se comportasse de maneira dúctil na ruptura.

\section{PROGRAMA EXPERIMENTAL}

Com base nos estudos de Sahb (2008) e Adorno (2004), desenvolveu-se essa pesquisa com as mesmas características básicas das peças e dos procedimentos experimentais, tais como: seção transversal do pilar, armaduras, conectores, tipo de concreto, e o procedimento de execução dos ensaios, de forma que se criem parâmetros que contribuam no processo de execução do reforço estrutural em que se utiliza esse tipo de conector.

Foram ensaiados cinco pilares de concreto armado, submetidos à flexo-compressão reta com excentricidade inicial de $60 \mathrm{~mm}$, baseados em pesquisas anteriores de Omar (2006), Sahb (2008) e Nascimento (2009), com o intuito de verificar a interação entre as superfícies do substrato e reforço.

As peças ensaiadas tinham seção retangular com dimensões de $120 \mathrm{~mm}$ x $250 \mathrm{~mm}$ e comprimento total de $2000 \mathrm{~mm}$, possuindo em suas extremidades consolos, armados, com o objetivo de resistir a grande concentração de tensões nessas regiões evitando a ruptura localizada e facilitando a aplicação e transmissão da carga excêntrica.

O reforço dos pilares foi desenvolvido utilizando uma camada de $35 \mathrm{~mm}$ de concreto para aumentar a seção transversal na região comprimida de maneira que os pilares reforçados tivessem seção transversal de $155 \mathrm{~mm}$ x $250 \mathrm{~mm}$. Para garantir maior interação entre o reforço e o substrato foram utilizados conectores do tipo AF da Âncora Sistema de Fixação. Os conectores eram compostos de porca, arruela, jaqueta e pino, fixados manualmente de maneira que ficasse $15 \mathrm{~mm}$ ancorado na camada de $35 \mathrm{~mm}$ reforço (Figura 6).

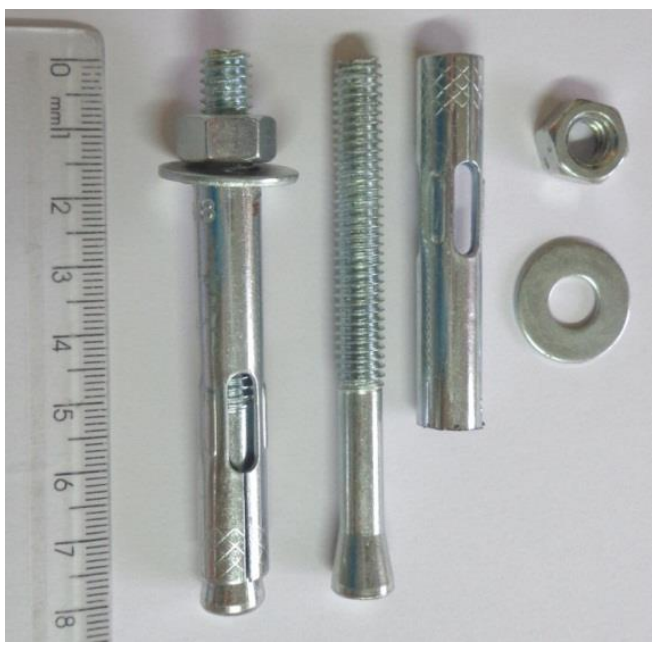

FIGURAS 6: a) parafuso completo, b) parafuso cônico, c) jaqueta, d) porca, e) arruela.

Foram realizadas duas concretagens utilizando concreto usinado auto adensável sendo realizados os devidos ensaios. $\mathrm{Na}$ primeira concretagem foram moldadas todas as peças originais e uma peça monolítica (dimensões das peças reforçadas), na segunda foram moldadas as camadas de reforço das peças originais.
Os ensaios foram divididos em duas séries, sendo a primeira com dois pilares, um original monolítico "PO" que possuía as dimensões $120 \mathrm{~mm}$ x 250 mm, um de referência monolítico "PR" com dimensões dos pilares reforçados, porém moldado em uma única concretagem. Na segunda série foram ensaiados três pilares reforçados com 
espaçamento vertical de $100 \mathrm{~mm}$ com a seguinte nomenclatura P100-26, P100-38 e P100-50. Durante a execução do ensaio do pilar P100-26 ocorreu um problema com o atuador hidráulico, sendo necessário interrompê-lo de forma que esse primeiro ensaio teve a nomenclatura de pilar P10026a e o reensaio da mesma peça até a ruptura, $\mathrm{P} 100-26 \mathrm{~b}$ com o uso apenas de um relógio $\mathrm{R} 3 \mathrm{e}$ trena. O posicionamento dos conectores é mostrado na Figura 7.

O procedimento de reforço dos pilares seguiu as seguintes etapas: identificação da posição dos estribos, locação da posição dos conectores, execução dos furos, escarificação, fixação dos conectores, limpeza, saturação e moldagem do concreto de reforço (Figura 8).

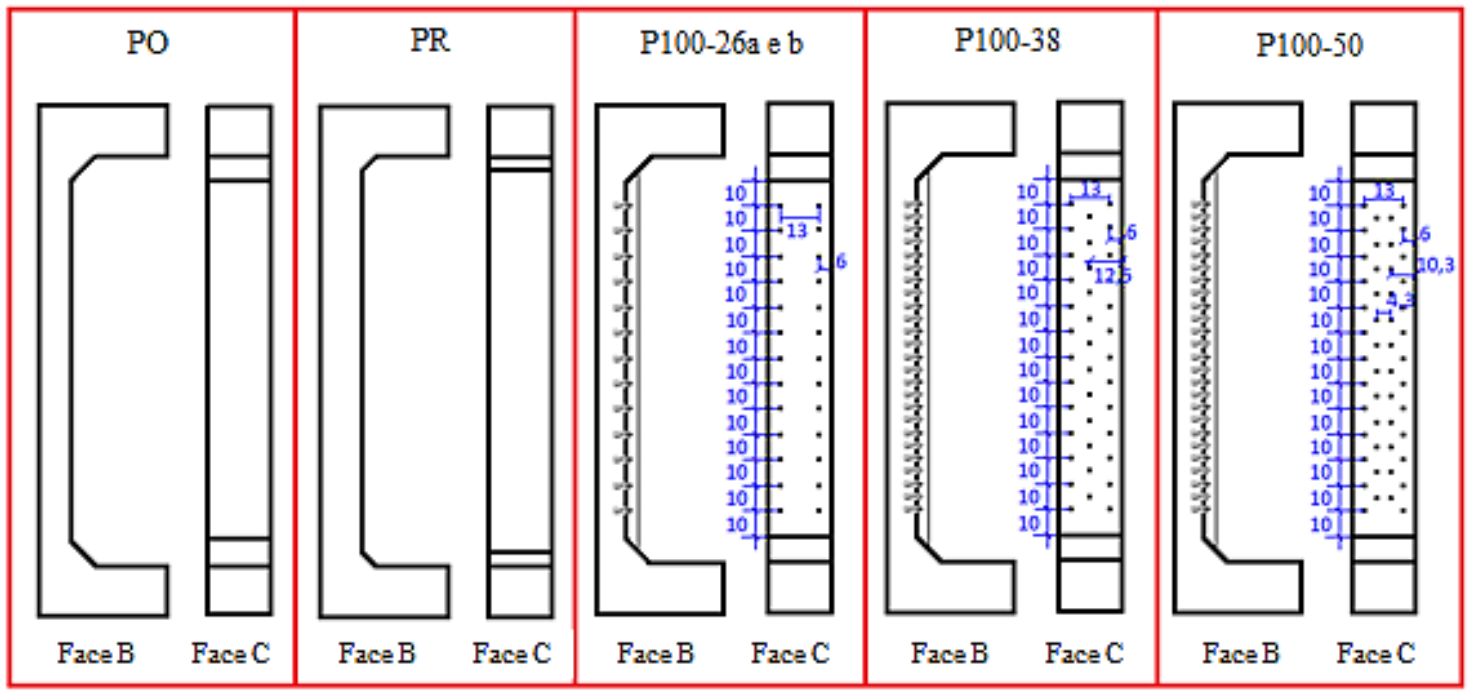

FIGURA 7: Mapeamento da posição dos conectores nos pilares reforçados P100-26a e b, P100-38 e P100-50 para execução dos furos e instalação dos componentes.

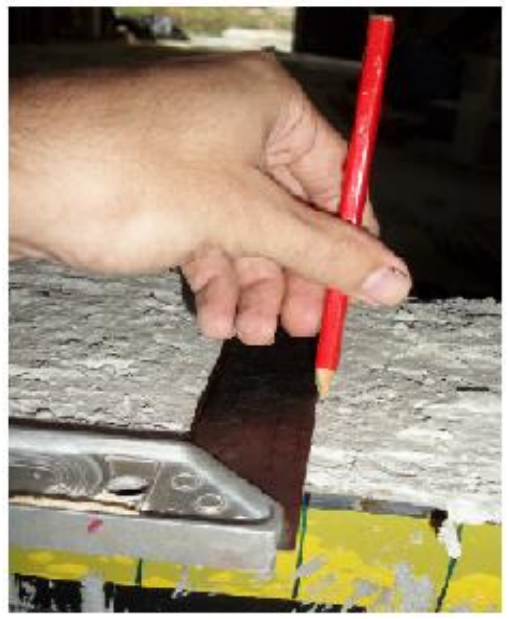

a- Localização dos estribos

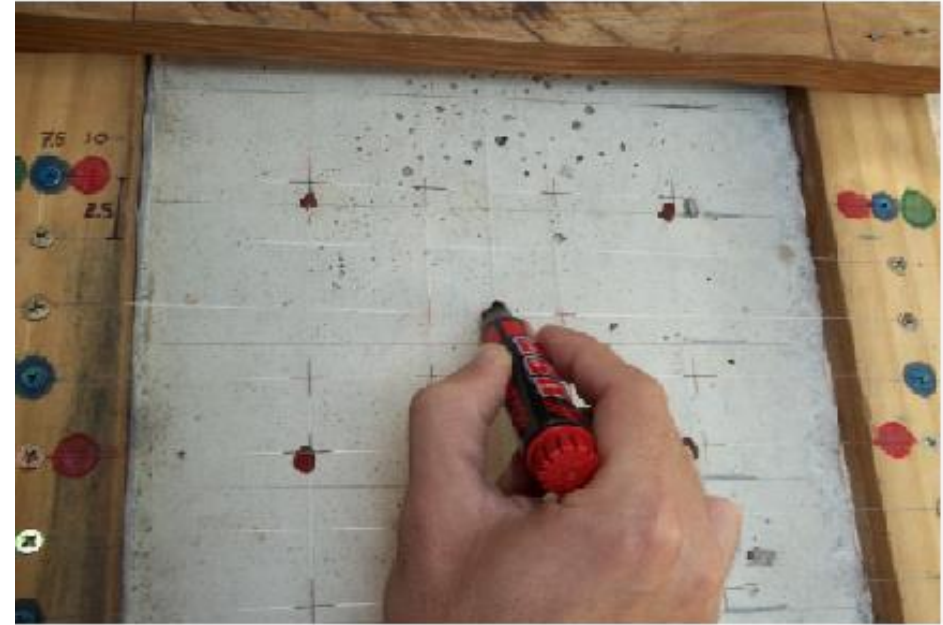

b- Posição dos conectores

FIGURA 8: Procedimentos de localização das armaduras transversais, marcação e execução dos furos, preparação da superfície onde será aplicado o reforço e instalação de conectores. 


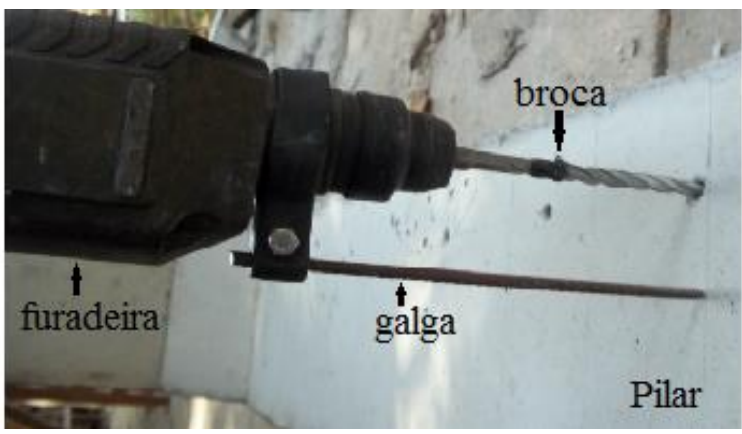

c- Execução de furos

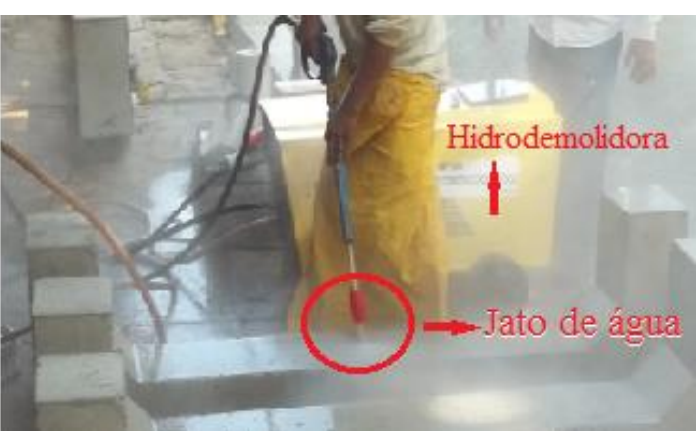

d- Escarificação

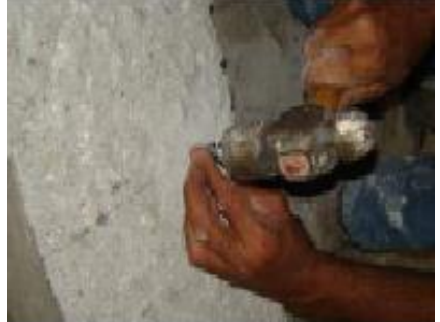

e- Instalação de conectores

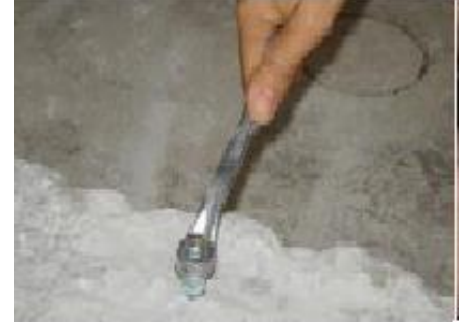

f- Aperto dos conectores

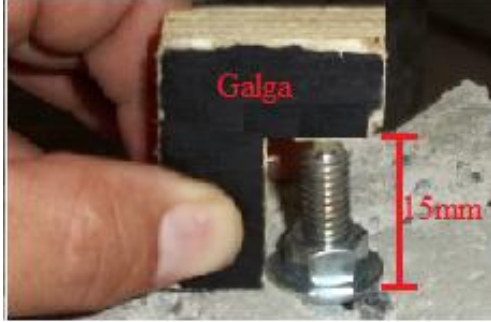

g- Aferição da altura

FIGURA 8: Procedimentos de localização das armaduras transversais, marcação e execução dos furos, preparação da superfície onde será aplicado o reforço e instalação de conectores. (Continuação...)

Para medir as deformações foram utilizados extensômetros de resistência elétrica da marca EXCEL, posicionados na região central dos pilares, instalados na armadura longitudinal e na superfície da camada de reforço de concreto.

$O$ processo de montagem do ensaio tem as seguintes etapas: posicionamento parcial da peça; instalação dos aparelhos de apoio; posicionamento da célula de carga; posicionamento final da peça; verificação do prumo; marcação e posicionamento dos aparelhos medidores.

As peças foram transportadas como auxílio de uma ponte rolante até o local de execução dos ensaios, sendo posicionadas previamente sobre uma estrutura metálica e imobilizada pelas travas de apoio, ficando erguidas previamente com o auxílio de um atuador hidráulico de $300 \mathrm{kN}$ até a posição necessária para o posicionamento de pequenas chapas metálicas onde o cursor dos relógios serão apoiados, e do atuador hidráulico definitivo. Foram utilizados corpos-de-prova para apoio da peça e substituição do atuador.

Foi feita a marcação da posição dos aparelhos de apoio afim de se garantir a excentricidade estipulada, e fixaram-se as chapas metálicas e os aparelhos de apoios com gesso pedra. Após a cura do gesso pedra dos apoios, posicionou-se a célula de carga ligada à leitora em funcionamento para que não ocorram erros de leitura de cargas e verificou-se o prumo, a peça foi erguida com o atuador hidráulico até a fixação completa.

Fixada a peça com a excentricidade e prumo corretos, foi feita a marcação e instalação dos relógios, trena, LVDT's, e extensômetros do concreto, conectaram-se os extensômetros ao aparelho transdutor e este ao computador, sendo feita uma leitura teste de todos os equipamentos.

Para monitorar os deslocamentos horizontais e verticais foram utilizados relógios comparadores e na região central utilizou-se além de um relógio uma trena (régua milimetrada).

O ensaio foi executado observando um passo de carga previamente estabelecido de $20 \mathrm{kN}$. A cada execução do devido passo de carga foi anotada a carga atuante, e feita a leitura dos extensômetros através do computador. As leituras dos relógios e as fissuras foram registradas nas planilhas e devidamente marcadas na peça com o uso de pincel atômico.

Os relógios comparadores foram retirados 
com cargas próximas da ruptura que eram monitoradas por meio de planilhas eletrônicas nas quais as deformações tanto das armaduras quanto do concreto eram comparadas com as deformações limites, a partir deste momento o passo de carga foi reduzido pela metade e a leitura do deslocamento horizontal era realizada apenas pela trena posicionada na região central da peça ensaiada até a ruptura com a devida carga registrada. O aparato experimental utilizado neste ensaio esta mostrado na Figura 9.

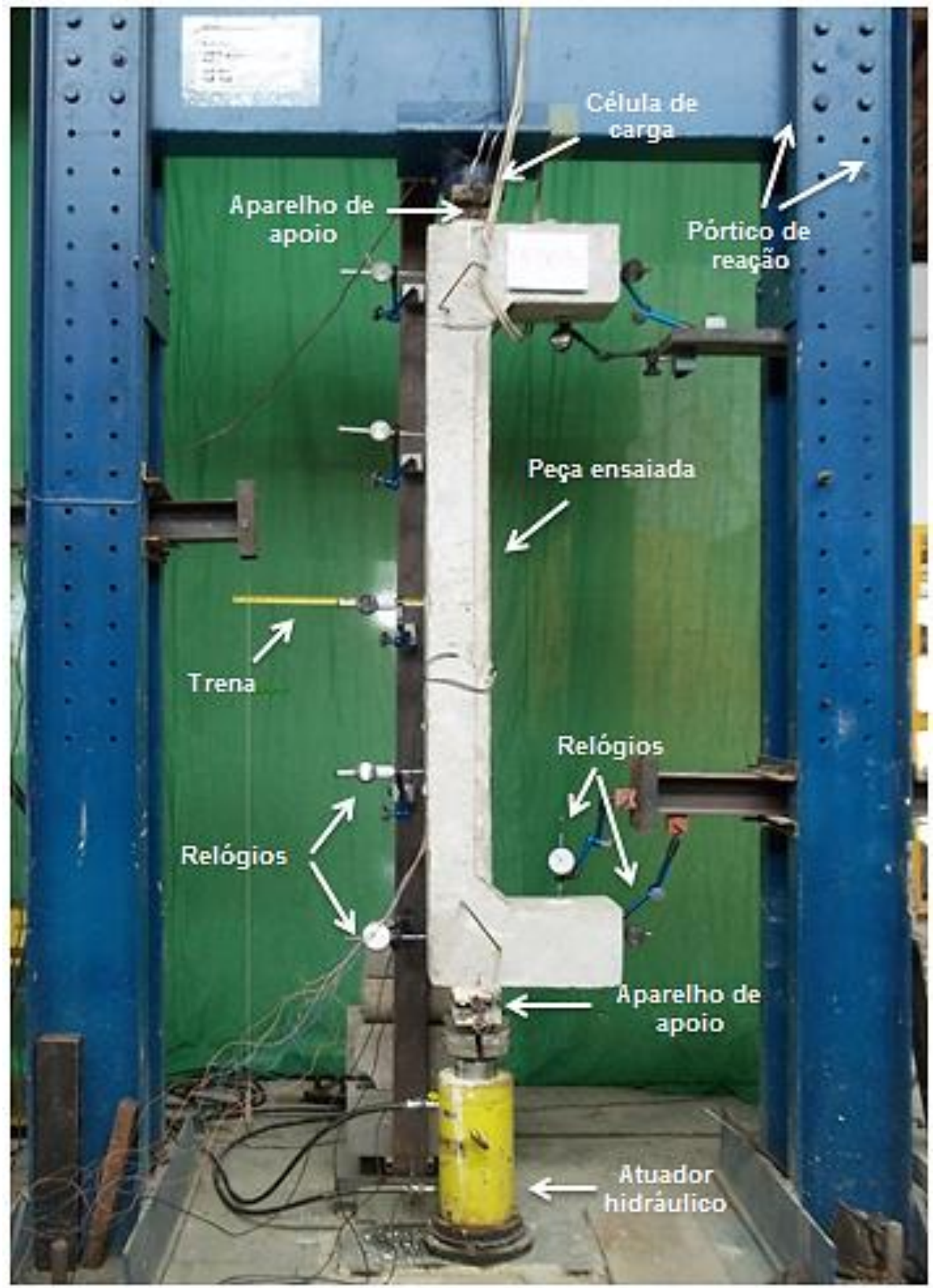

FIGURA 9: Pilar posicionado para execução de ensaio por flexo- compressão reta.

\section{RESULTADOS E DISCUSSÕES}

\subsection{DESLOCAMENTOS}

Os deslocamentos estão apresentados nas figuras 10 a 15 , onde $\mathrm{P}_{\mathrm{u}}$ carga de ruptura, $\mathrm{P}_{\mathrm{u}}^{\text {lei }}$ carga que retirou os relógios, $f_{\mathrm{c}}^{\text {sub }}$ resistência a compressão do concreto do substrato, $f_{\mathrm{c}}^{\text {ref }}$ resistência a compressão do concreto do reforço, $\mathrm{e}_{\text {inc }}$ excentricidade inicial, $\delta_{\max }$ deslocamento máximo. 

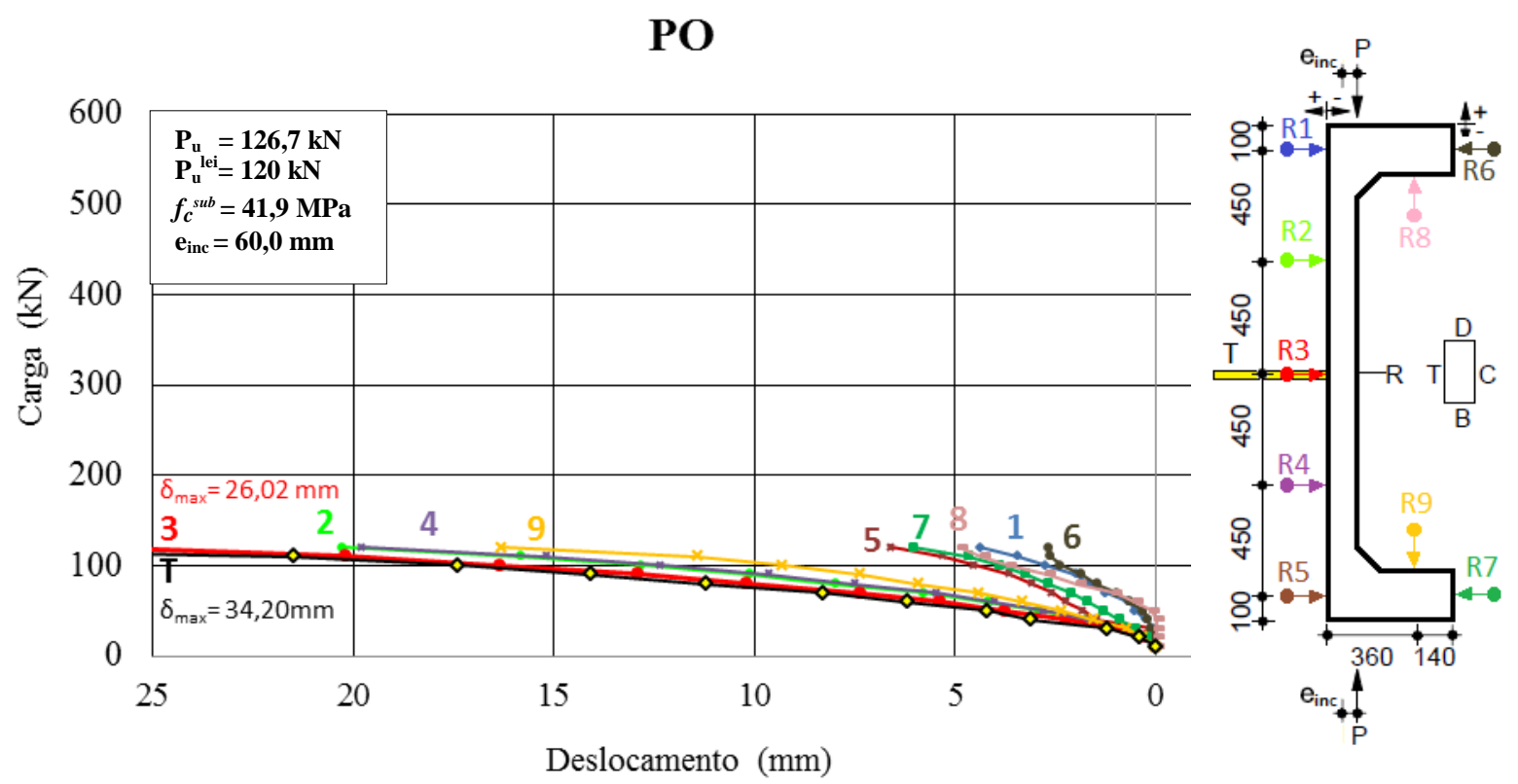

FIGURA 10: Deslocamentos horizontais e verticais PO.
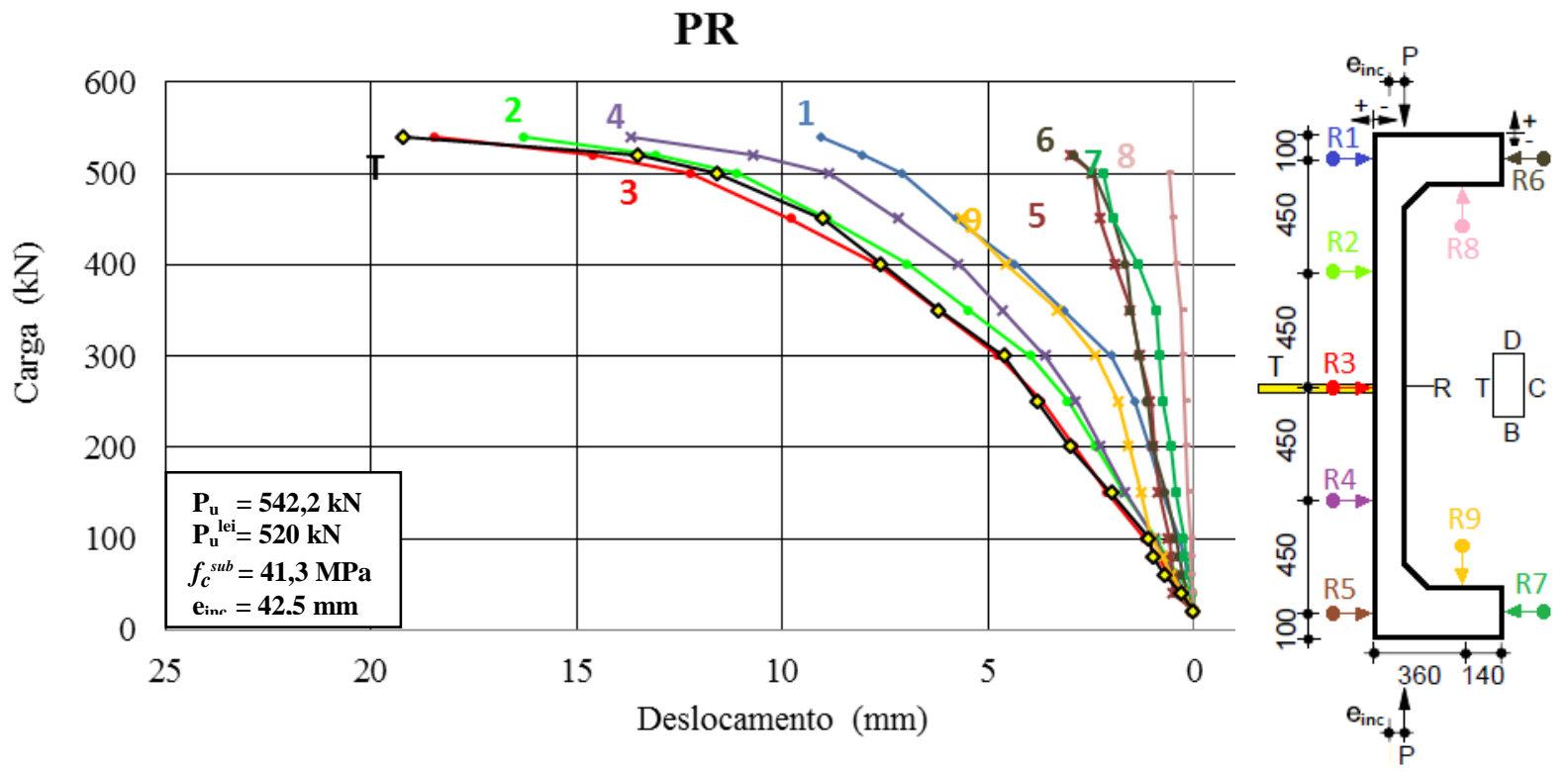

FIGURA 11: Deslocamentos horizontais e verticais PR. 


\section{P100-26a}
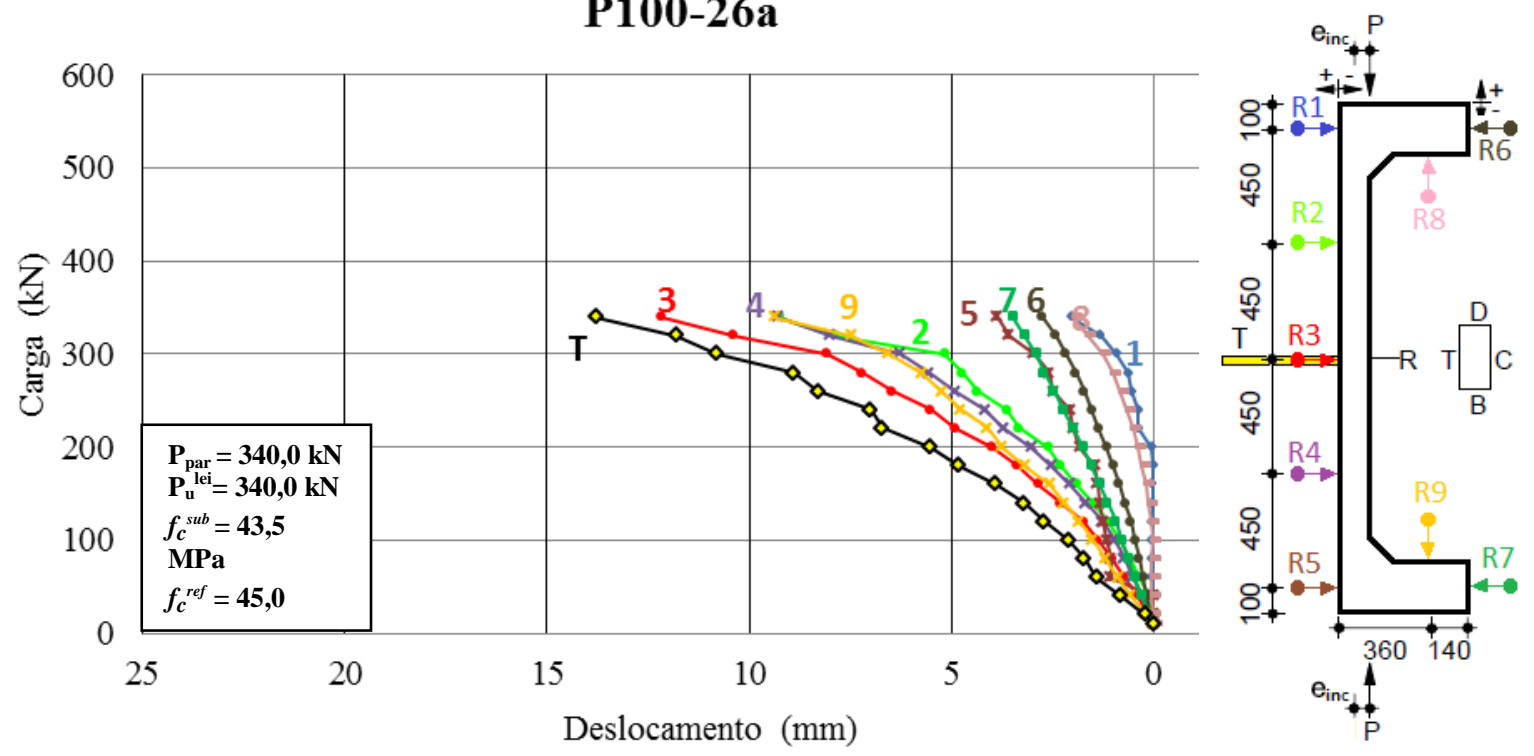

FIGURA 12: Deslocamentos horizontais e verticais $P 100-26 a$.
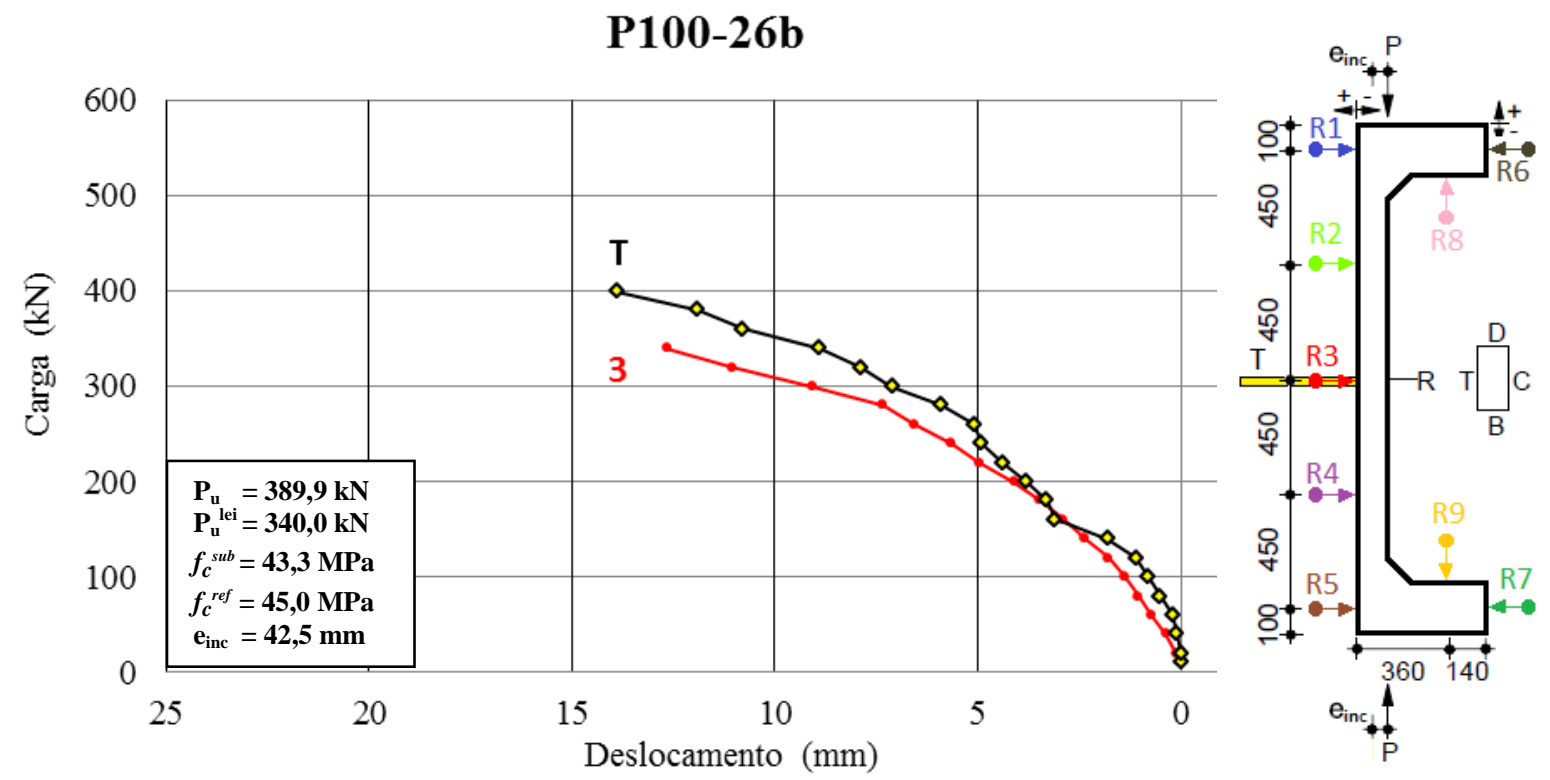

FIGURA 13: Deslocamentos horizontais e verticais P100-26b. 


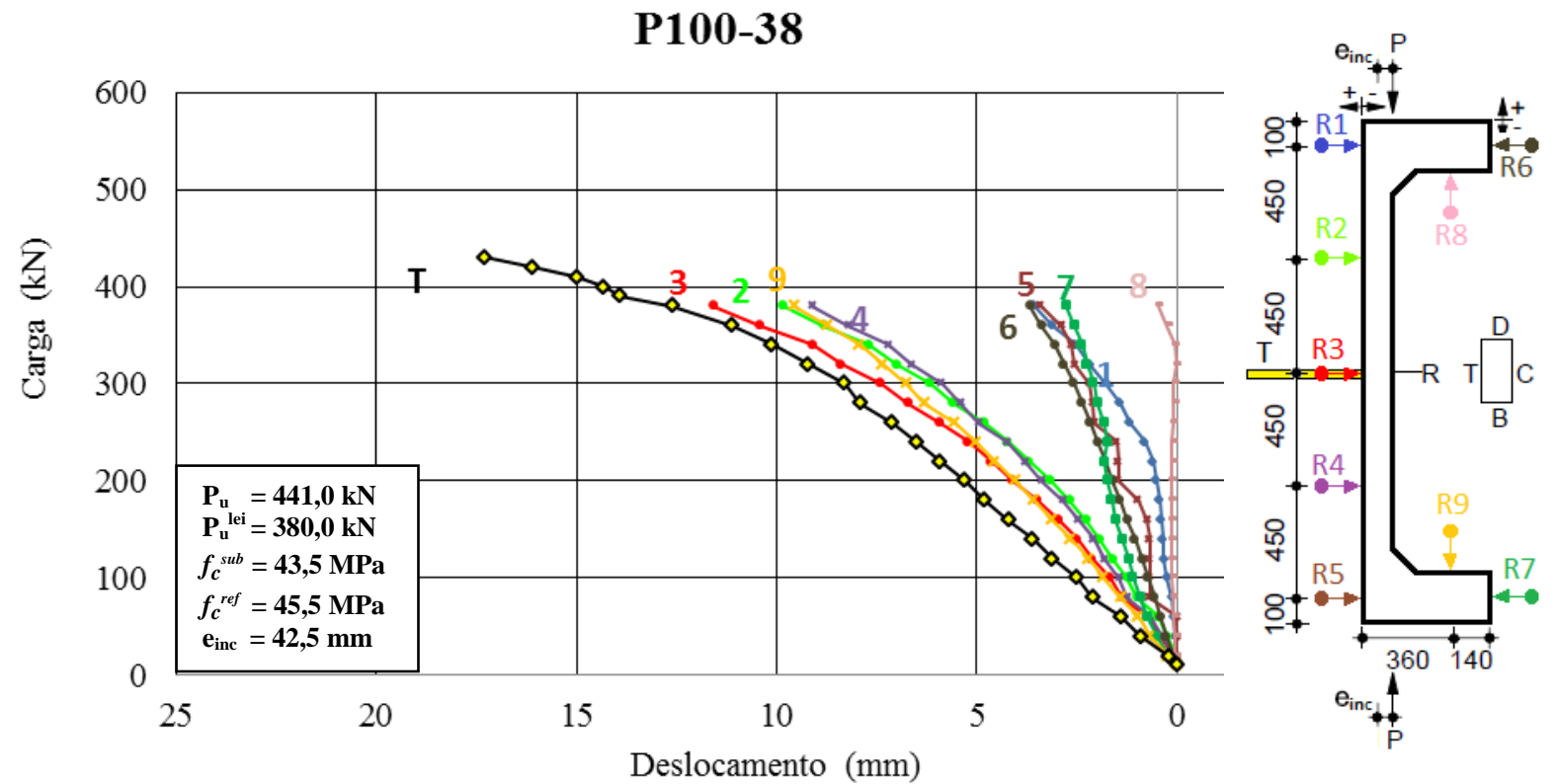

FIGURA 14: Deslocamentos horizontais e verticais P100-38.

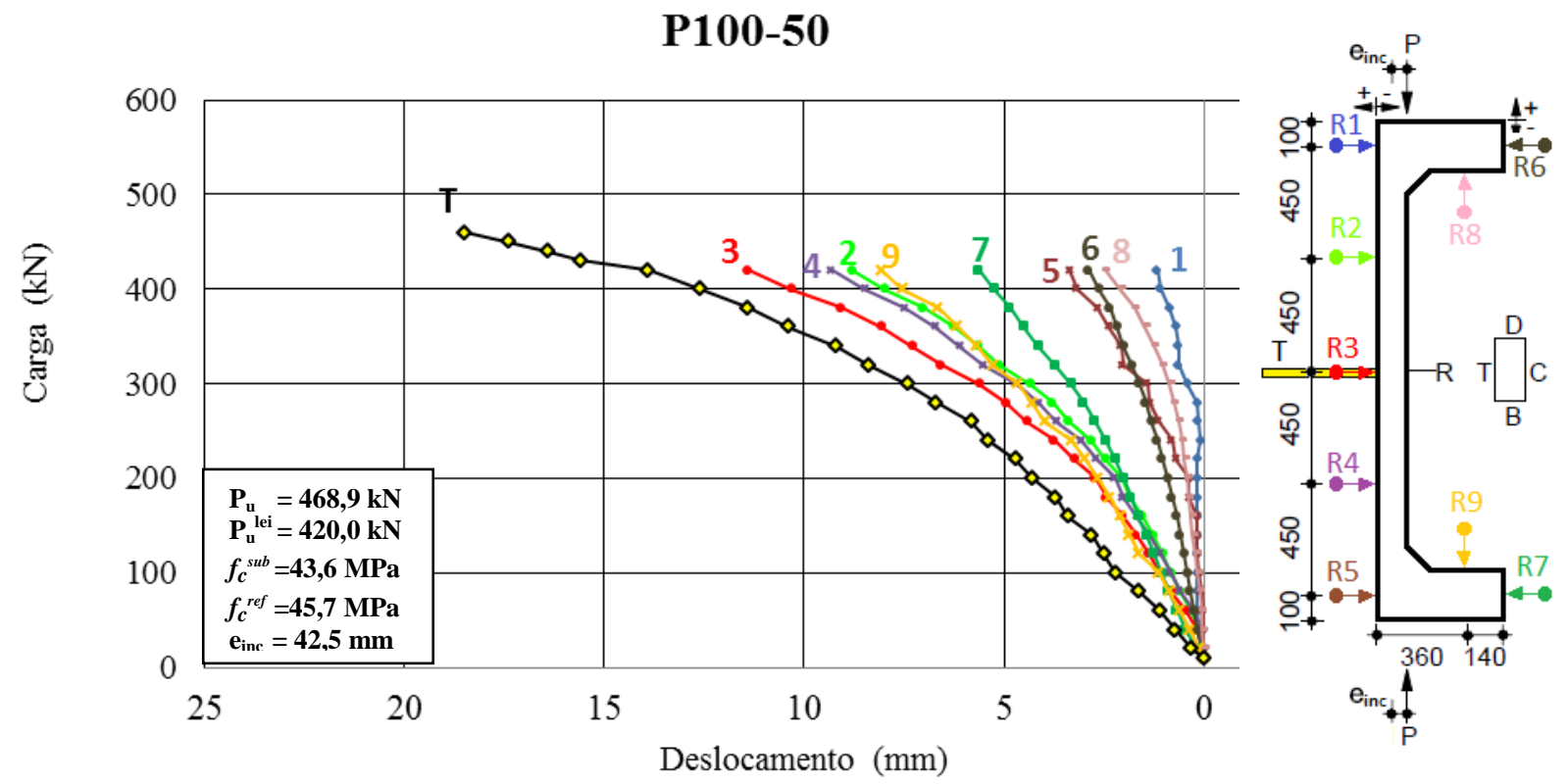

FIGURA 15: Deslocamentos horizontais e verticais P100-50.

Em todos os pilares o maior deslocamento horizontal ocorreu no relógio R3 e na trena $T$, situados na região central das peças. Os relógios $\mathrm{R} 2$ e R4 posicionados simetricamente na face tracionada das peças apresentaram em todos os casos comportamento simétrico ou bem próximo da simetria, mostrando certa eficiência no posicionamento das peças com a excentricidade requerida.

O relógio R9 posicionado no consolo inferior teve um grande deslocamento se comparado ao seu simétrico R8, isso se deve o fato de a aplicação da carga ser efetuada diretamente no consolo inferior, enquanto no R8 o pórtico de reação restringe esse deslocamento.

Observa-se que PO teve o maior deslocamento apesar da menor carga de ruptura, seguido pelo PR, outra informação a ser observada é que nos pilares reforçados o deslocamento foi diretamente proporcional à quantidade de 
conectores, de forma que os pilares reforçados se aproximaram do deslocamento de PR, como pode ser visto na Figura 16. A linha pontilhada na Figura 16 indica o deslocamento limite DL no estado limite de serviço (E.L.S.) recomendado pela NBR 6118: 2007 de l/250, onde l é o comprimento da peça.

A Tabela 1 apresenta as cargas em que os pilares atingiram o deslocamento limite, e a relação com a carga de ruptura. Com exceção do pilar PO que atingiu o deslocamento limite com $59 \%$ da carga de ruptura os demais pilares atingiram o deslocamento limite com carregamento próximo da ruína, cerca de $70 \%$ da carga de ruptura.

\subsection{CARGAS E MODO DE RUPTURA}

A carga e o modo de ruptura obtidos nos ensaios dos pilares são apresentados na Tabela 2

TABELA 1: Relação carga de ruptura x carga que atingiu o deslocamento limite DL.

\begin{tabular}{cccc} 
Pilar & $\mathbf{P}_{\mathrm{u}}(\mathbf{k N})$ & $\mathbf{P}_{\mathrm{DL}}(\mathbf{k N})$ & $\mathbf{P}_{\mathrm{DL}} / \mathbf{P}_{\mathrm{u}}$ \\
\hline $\mathrm{PO}$ & 126,7 & 75,0 & 0,59 \\
\hline $\mathrm{PR}$ & 542,2 & 420,0 & 0,77 \\
\hline P100-26b & 389,9 & 290,0 & 0,74 \\
\hline P100-38 & 441,0 & 316,0 & 0,72 \\
\hline P100-50 & 468,9 & 365,0 & 0,78 \\
\hline
\end{tabular}

$\mathrm{P}_{\mathrm{DL}}$ : Carga quando o deslocamento atingiu o deslocamento limite $\mathrm{I} / 250=2000 / 250=8 \mathrm{~mm}$

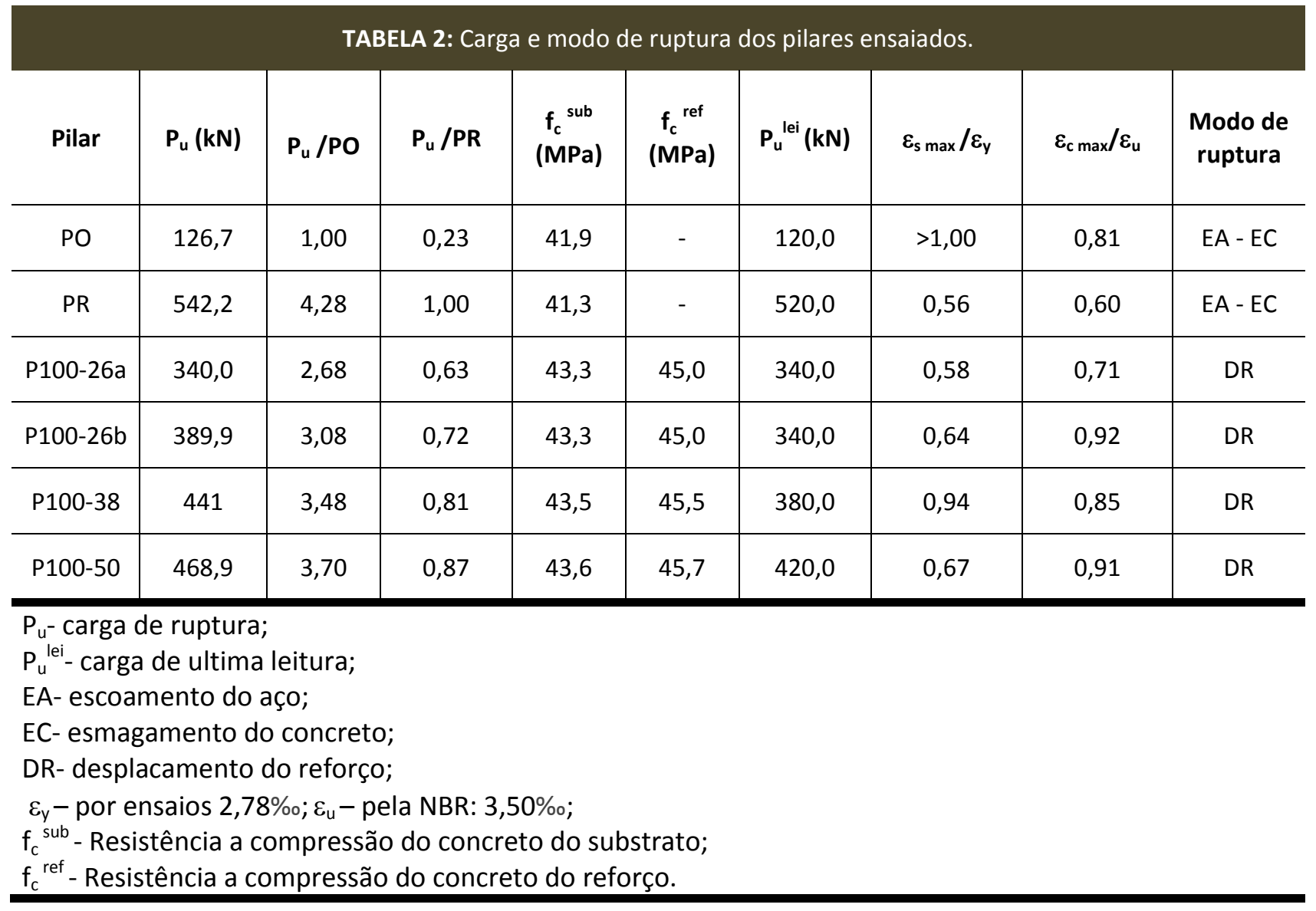


Os pilares reforçados apresentaram no geral um aumento da capacidade portante em cerca de mais de três vezes, porém nenhum superou a carga de ruptura do pilar PR. Todos os pilares reforçados tiveram como modo de ruptura o desplacamento da camada de reforço, com o concreto desta camada chegando ao esmagamento enquanto o PO e o PR tiveram como modo de ruptura o escoamento do aço e esmagamento do concreto.

Com relação à quantidade de conectores, houve um aumento da carga de ruptura conforme se aumentava a quantidade de conectores.

Observa-se que no P100-38 mesmo ocorrendo o escoamento do aço e esmagamento do concreto a ruptura ocorreu por desplacamento da camada de reforço. A Figura 17 mostra o aspecto visual da superfície de ruptura das peças.

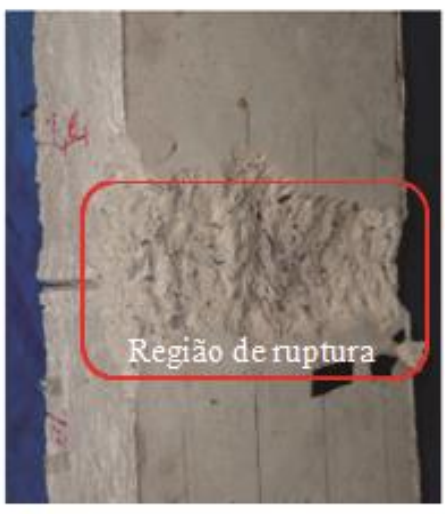

PO

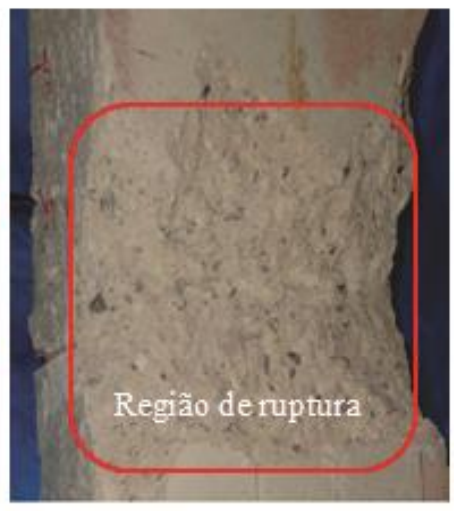

PR

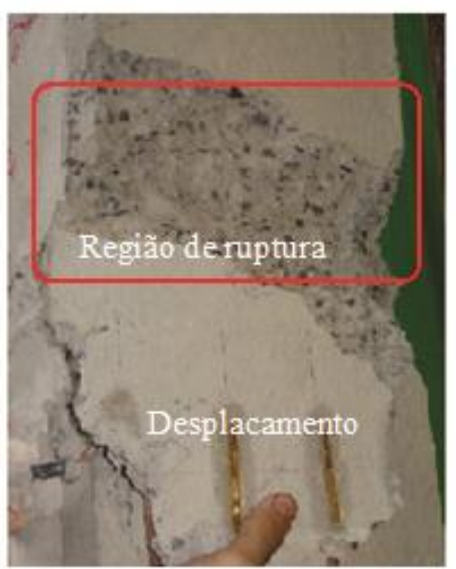

P100-26

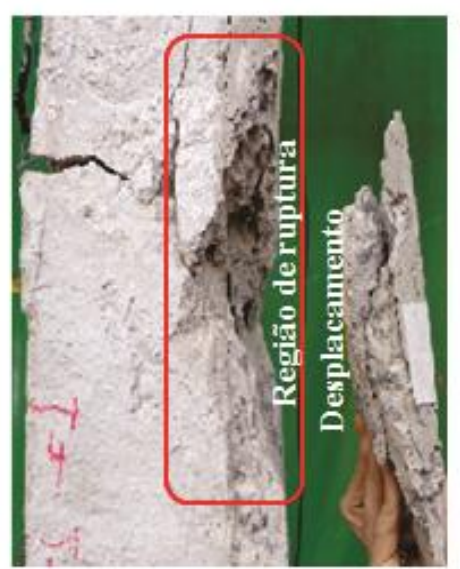

P100-38

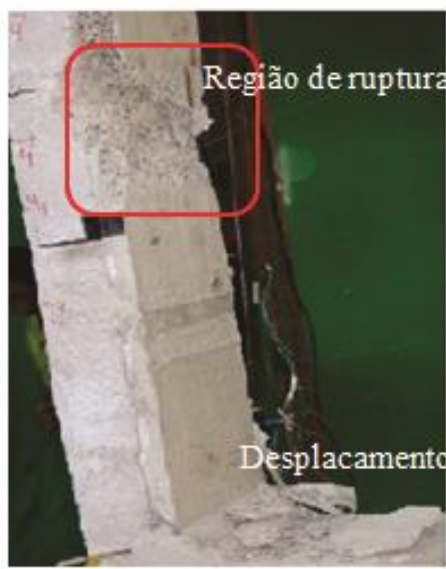

P100-50

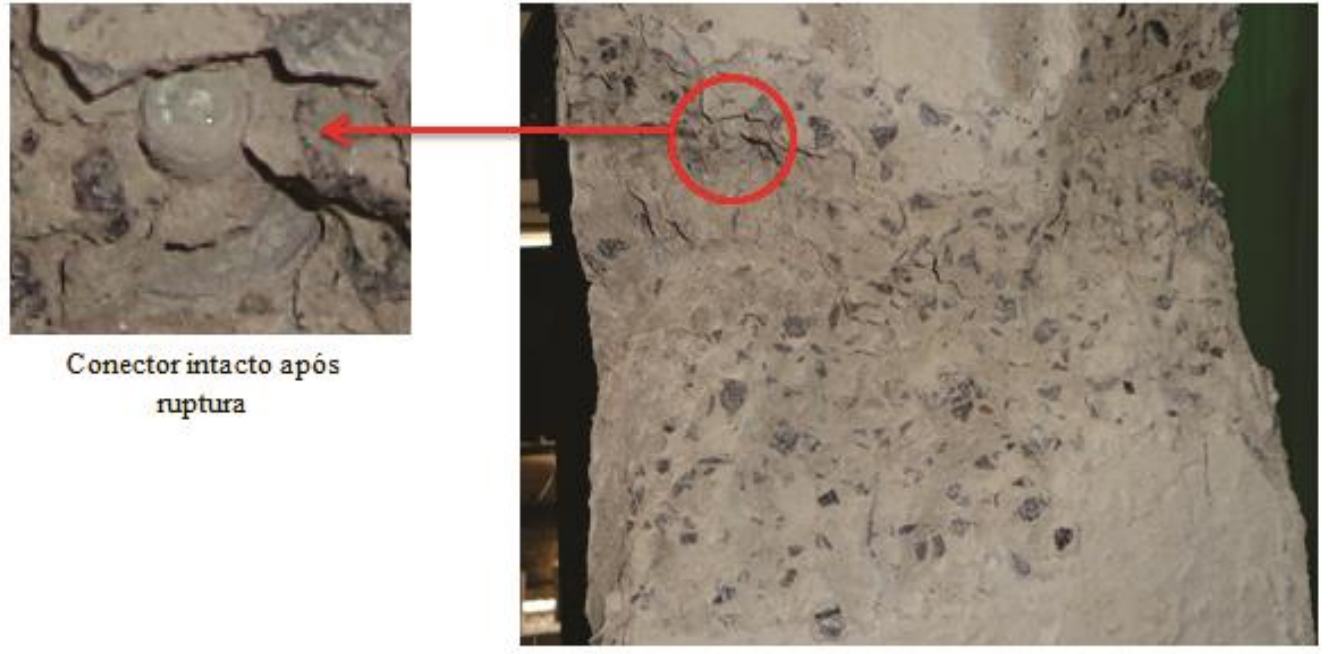

FIGURA 17: Aspecto visual do modo de ruptura dos pilares 


\subsection{COMPARATIVOS COM ESTUDOS CITADOS}

Os pilares das pesquisas citadas apresentam algumas características semelhantes aos pilares ensaiados, como excentricidade, seção transversal, armaduras dos pilares originais. No estudo de Sahb (2008) o pilar PB-R9-8 tinham a mesma quantidade de conectores que o pilar reforçado P100-26. Os pilares de Omar (2006) se aproximam em taxa de conectores dos pilares reforçados e os pilares de Nascimento (2009) são reforçados na mesma região dos pilares deste estudo.

O Pilar P100-26 apresentou carga de ruptura menor com relação a $\mathrm{PB}-\mathrm{R} 9-8^{\mathrm{S}}$ de Sahb (2008), que são iguais em distribuição e número de parafusos com diferença apenas no espaçamento dos conectores, essa diferença de carga de ruptura pode ser relacionada à diferença de resistência característica à compressão do concreto, uma vez que o pilar PB-R9-8 ${ }^{S}$ obteve resistência maior da camada de reforço em cerca de $15 \%$ com relação ao pilar P100-26 além da instalação de armadura de combate à retração em PB-R9-8 .

Com relação aos pilares de Omar (2006), o pilar $\mathrm{PC} 35^{\circ}$ apresentou carga de ruptura próxima à do pilar P100-26 que por sua vez apresenta uma taxa de conectores maior, podendo ser justificado pela proximidade da resistência característica a compressão da camada de reforço do concreto de ambos os pilares.

Os pilares de Nascimento (2009) tiveram carga de ruptura cerca de quatro vezes maior que a do pilar original PO mesmo com a taxa de armadura pequena e a resistência característica à compressão do concreto menor. Este resultado pode ser explicado técnica de reforço empregada na qual eram confeccionados sulcos onde os conectores eram instalados e concretados aumentando a aderência entre os materiais de tal forma que das pesquisas apresentadas o pilar $\mathrm{P} 8^{\mathrm{N}}$ foi o único pilar reforçado que não rompeu por desplacamento da camada de reforço e sim por esmagamento do concreto. Os resultados comparativos entre os estudos citados estão apresentados na Tabela 3.

\begin{tabular}{|c|c|c|c|c|c|c|c|}
\hline Pilar & $P_{u}(k N)$ & $f_{c}^{s u b}(\mathrm{MPa})$ & $\begin{array}{c}f_{c}^{r e f} / f_{c}^{\text {sub }} \\
P R\end{array}$ & $\begin{array}{c}f_{c}^{r e f} \\
(\mathrm{MPa})\end{array}$ & $\mathrm{T}_{\mathrm{ch}}(\%)$ & $P_{u} / P_{u}(P O)$ & $P_{u} / P_{u}(P R)$ \\
\hline PO & 126,7 & 41,9 & - & - & - & 1,00 & 0,23 \\
\hline PR & 542,2 & 41,3 & - & - & - & 1,28 & 1,00 \\
\hline P100-26 & 389,9 & 43,3 & 1,09 & 45,0 & 0,37 & 3,08 & 0,72 \\
\hline P100-38 & 441,0 & 43,5 & 1,10 & 45,5 & 0,55 & 3,48 & 0,81 \\
\hline P100-50 & 469,9 & 43,6 & 1,11 & 45,7 & 0,72 & 3,70 & 0,87 \\
\hline PA-R9 ${ }^{\mathrm{S}}$ & 553,4 & 39,9 & 1,26 & 52,0 & 0,25 & 4,36 & 1,02 \\
\hline PB-R9-8 ${ }^{\mathrm{S}}$ & 626,3 & 41,2 & 1,27 & 52,5 & 0,37 & 4,94 & 1,16 \\
\hline $\mathrm{PC}^{\circ} 5^{\circ}$ & 380,0 & 25,1 & 1,12 & 46,2 & 0,24 & 3,00 & 0,70 \\
\hline $\mathrm{PC}^{2} 5^{\circ}$ & 506,0 & 21,5 & 1,13 & 46,8 & 0,24 & 3,99 & 0,93 \\
\hline $\mathrm{P} 7^{\mathrm{N}}$ & 480,0 & 38,5 & 0,85 & 35,0 & 0,04 & 3,80 & 0,89 \\
\hline $\mathrm{P} 8^{\mathrm{N}}$ & 520,0 & 38,2 & 0,84 & 34,5 & 0,07 & 4,10 & 0,96 \\
\hline \multicolumn{8}{|c|}{ Pilares: $\mathrm{P}^{\mathrm{S}}$ Sahb (2008), $\mathrm{P}^{\mathrm{O}}$ Omar (2006), $\mathrm{P}^{\mathrm{N}}$ Nascimento (2009) } \\
\hline \multicolumn{8}{|c|}{$\mathrm{T}_{\mathrm{ch}}$ : Taxa de conectores. } \\
\hline
\end{tabular}




\section{CONCLUSÕES}

Todos os pilares reforçados apresentaram carga de ruptura maior que o pilar original PO e menor que o pilar PR, destacando dentre os pilares reforçados o pilar P100-50 que possuía a maior taxa de conectores com a maior carga de ruptura e o pilar P100-26 que possuía a menor taxa de conectores com a menor carga de ruptura, reforçando a relação entre taxa de conectores e carga de ruptura.

O pilar com a maior quantidade de conectores P100-50 rompeu com desplacamento da camada de reforço e também foi evidenciada tendência de esmagamento do concreto na região central do pilar,

O comportamento do pilar P100-50 apresentou deslocamento mais próximo do pilar monolítico de referência $\mathrm{PR}$, todos os pilares reforçados tiveram uma rigidez menor com relação ao pilar monolítico PR.

Nos demais pilares reforçados, registrouse deformação característica tendenciando ao esmagamento do concreto na face mais comprimida e no Pilar P100-38 registrou-se deformação característica do aço que indica o escoamento, porém não se pode concluir que tenham rompido por esmagamento ou escoamento, uma vez que ocorreu o desplacamento da camada de reforço na carga última.

Em todos os pilares a ruptura ocorreu na região central, não sendo registrado em nenhum caso ruptura nas extremidades por concentração de tensão, mostrando a eficiência dos consolos.

A ductilidade dos pilares ensaiados foi diretamente proporcional à quantidade de conectores utilizados. Também se observou que nenhum conector rompeu por cisalhamento.

São necessários maiores estudos no que se diz respeito à aderência do concreto das diferentes idades, dado o fato do desplacamento momentos antes da ruptura.

\section{AGRADECIMENTOS}

À sociedade brasileira que por meio da Capes, CNPq e juntamente com as empresas
Realmix, Carlos Campos Consultoria e Construções Limitada, que disponibilizaram bolsa de estudos e financiaram os materiais necessários para o estudo.

\section{REFERÊNCIAS BIBLIOGRÁFICAS}

ABNT: Associação Brasileira de Normas Técnicas. NBR 6118:2003 - Projeto de estruturas de concreto - Procedimento. Rio de Janeiro, 2003.

ACI COMMITTEE 318. Building Code Requirements for Reinforced Concrete and Commentary - $\mathrm{ACl}$ 318M/02. Detroit, American Concrete Institute, 2001.

ADORNO, A. L. C. Análise Teórica e Experimental de Pilares em Concreto Simples e Armado sob Flexo-Compressão Reta. Tese (Doutorado) Departamento de Engenharia Civil e Ambiental/UnB, Brasília, DF. 399 p. 2004.

GOMES, A \& APPLETON, J. Strengthening of reinforced concrete structures by use of jacketing. RPEE, Lisboa, 1998.

NASCIMENTO, P. P. Análise Experimental de Pilares de Concreto Armado Submetidos à FlexoCompressão, Reforçados com Concreto Auto Adensável e Conectores. Dissertação (Mestrado), UFG, Goiânia, Goiás, 2009.

OMAR, M. Y. M. Análise Experimental de Pilares de Concreto Armado Reforçados com Concreto Auto Adensável (CAA). Dissertação (Mestrado), UFG, Goiânia, Goiás, 2006.

OMAR, M. Y. M. Experimental analysis of reinforced concrete columns strengthened with self-compacting concrete. IBRACON Structures and Materials Journal, 2010.

SAHB, K. F. P. Análise Experimental de Pilares de Concreto Armado Submetidos à FlexoCompressão, Reforçados com Concreto Auto Adensável e Chumbadores. Dissertação (Mestrado) CMEC/EEC/UFG, Goiânia, Goiás. 224p. 2008.

VALLE, E.G. (1983). Estruturas de Hormigón Armado: refuerzo mediante hormigón y estructura metálica. In: Curso de rehabilitacion: 5. La Estructura. Madrid, Colégio Oficial de Arquitectos de Madrid. 1983. 